\title{
Effect of the timing of discontinuation of last-line chemotherapy on patient prognosis in advanced and recurrent gastric cancer
}

\author{
MICHIO KIMURA $^{1}$, SHIORI KAWACHI ${ }^{1}$, MAKIKO GO $^{1}$, MINA IWAI $^{1}$, EISEKI USAMI ${ }^{1}$, \\ HITOMI TERAMACHI $^{2}$ and TOMOAKI YOSHIMURA ${ }^{1}$ \\ ${ }^{1}$ Department of Pharmacy, Ogaki Municipal Hospital, Ogaki, Gifu 503-8502; \\ ${ }^{2}$ Laboratory of Clinical Pharmacy, Gifu Pharmaceutical University, Gifu 501-1196, Japan
}

Received June 27, 2018; Accepted October 19, 2018

DOI: $10.3892 / \mathrm{mco} .2018 .1753$

\begin{abstract}
The present study aimed to determine the effect of the timing of treatment discontinuation on the prognosis of patients with advanced and recurrent gastric cancer chemotherapy. Between July 2014 and March 2017, 127 patients who underwent chemotherapy for advanced and recurrent gastric cancer at Ogaki Municipal Hospital (Ogaki, Japan) were examined. To determine factors associated with survival, multivariate analysis using the Cox proportional hazards model, and hazard ratios and their $95 \%$ confidence intervals (95\% CI) were calculated. The reasons for discontinuation of last-line chemotherapy and the last hospitalization prior to mortality were surveyed. Age ( $\leq 51$ years), number of treatment lines ( $\leq 1$ line), and days between last dose of the final chemotherapy regimen and death ( $\leq 79$ days) were independently and significantly associated with survival in the multivariate analysis. Compared with patients who did not receive chemotherapy in the last 79 days of life, those who received chemotherapy in the last 79 days of life days had a hazard ratio of 1.858 (95\% CI, 1.059-3.261; $\mathrm{P}=0.031)$ for mortality. A decrease in the performance status was responsible for treatment discontinuation in 51 of 75 cases among patients who received chemotherapy in the last 79 days of life and 9 of 26 cases among patients who did not receive chemotherapy in this duration $(\mathrm{P}<0.001)$. Among patients who received chemotherapy in the last 79 days of life, 67 patients were hospitalized prior to mortality; among patients who did not receive chemotherapy in this duration, 15 patients were hospitalized prior to mortality $(\mathrm{P}<0.001)$. In conclusion, continuation of chemotherapy until just prior to mortality does not prolong the survival time in patients with advanced and recurrent gastric cancer.
\end{abstract}

Correspondence to: Mr. Michio Kimura, Department of Pharmacy, Ogaki Municipal Hospital, 4-86 Minaminokawa, Ogaki, Gifu 503-8502, Japan

E-mail: kimkim0305nao@yahoo.co.jp

Key words: gastric cancer, chemotherapy, prognostic factor, medication discontinuation, overall survival

\section{Introduction}

In advanced and recurrent gastric cancer chemotherapy, the first line of chemotherapy includes tegafur-gimeracil-oteracil-potassium (S-1) plus cisplatin; capecitabin plus cisplatin; capecitabin plus oxaliplatin; S-1 plus oxaliplatin; folinic acid, fluorouracil and oxaliplatin; and capecitabin/S-1, cisplatin and trastuzumab (1-10). The second line of therapy includes paclitaxel plus ramcirumab (11), and the third line includes nivolumab or irinotecan $(12,13)$. Owing to recent progress in the field, chemotherapy has a high response rate (tumor shrinkage) in advanced and recurrent gastric cancer (1-13).

The American Society of Clinical Oncology advocates that treatment with unclear evidence of efficacy should not be performed unnecessarily (14). In a randomized controlled trial involving patients with metastatic non-small cell lung cancer, patients who did not received chemotherapy in the last 2 months of life had longer survival times compared with those who received chemotherapy in the last 2 months of life (15). In lung cancer patients who survived at least 3 months from diagnosis, patients who received cancer chemotherapy in the last 2 weeks of life showed no improvement in the prognosis as compared with patients who stopped anticancer drug treatment at an earlier stage (16). Thus, despite a good overall physical condition, if the tumor is exacerbated during administration of the anticancer agents but the efficacy of anticancer drugs has not been confirmed thereafter, it is necessary to consider discontinuation of treatment. However, in clinical practice, cancer chemotherapy is often continued for several weeks prior to mortality. In patients with advanced and recurrent gastric cancer, the association between treatment at the final stage of life and prognosis has not been reported thus far, to the best of our knowledge. Generally, prognosis indicates the medical outlook for future symptoms (including progression of the disease, effect of treatment and probability of survival). In the present study, 'better prognosis' was set as extending survival time while avoiding reduced quality of life.

At present, pharmacists serve an important role in cancer chemotherapy and palliative care by contributing to the anticancer drug design, supportive therapy and collection of patient information. As a member of the oncology team, pharmacists must provide information to carefully decide on 
a change in or discontinuation of cancer chemotherapy at the final stage of life on the basis of medical appropriateness.

Therefore, to determine the prognostic factors and effect of timing of discontinuing treatment on patient prognosis, the survival period following chemotherapy was examined in patients who received chemotherapy for advanced and recurrent gastric cancer.

\section{Patients and methods}

Patients. Between July 2014 and March 2017, 127 patients who underwent chemotherapy for advanced and recurrent gastric cancer in the gastroenterology and gastrointestinal surgerical department at Ogaki Municipal Hospital (Ogaki, Japan), were included in the present study. Patients who transferred to other hospitals during treatment were excluded $(n=8)$. In addition, patients continuing treatment from prior to this period were also excluded $(n=16)$. Overall survival (OS) and reasons for and timing of discontinuation of last-line chemotherapy were surveyed retrospectively. Furthermore, the reasons for the last hospitalization of life were reported.

The selected patients were divided in two groups: i) Patients who had received chemotherapy in the last 79 days of life, and ii) patients who had not received chemotherapy in the last 79 days of life.

Ethical considerations. Personal information was protected in the aggregated data. The present study was approved by the Institutional Review Board of Ogaki Municipal Hospital (no. 20170223-3). The requirement for informed consent was waived by the Institutional Review Board.

Statistical analysis. The primary outcome was OS, which was defined as the period from the date of treatment onset to the date of mortality from any cause. To determine factors associated with survival, univariate and multivariate analysis using the Cox proportional hazards model, and hazard ratios and their $95 \%$ confidence intervals $(95 \% \mathrm{CI})$ were calculated. Patients were categorized into the abovementioned 2 groups according to the receiver operating characteristics curves for optimal cut-off values of each factor. Distributions of reasons for treatment discontinuation were assessed using the $\chi^{2}$ test. $\mathrm{P}<0.05$ was considered to indicate a statistically significant difference and all statistical analyses were performed using EZR software (version 1.30; Saitama Medical Center, Jichi Medical University, Saitama, Japan), a graphical user interface for R (The R Foundation for Statistical Computing, Vienna, Austria) (17).

\section{Results}

Patient characteristics. The patient characteristics are presented in Table I. The median age of patients was 67 years (range, 33-84 years), the median number of treatment lines was 2 (range, 1-5 lines), and the median OS was 246 days (range, 31-1,188 days). Furthermore, 17.8, 41.6 and $66.3 \%$ of patients received chemotherapy in 14,30, and 60 days prior to mortality, respectively.

Prognostic factors among patients with advanced and recurrent gastric cancer who received chemotherapy. Multivariate analyses of the baseline and clinical characteristics are presented as prognosticators in Table II. In the univariate analysis, age $(\leq 51$ years; $\mathrm{P}=0.016)$ and number of treatment lines $(\leq 1$ line; $\mathrm{P}<0.001$ ) were significantly associated with survival (data not shown). In the multivariate analysis, age ( $\leq 51$ years), number of treatment lines ( $\leq 1$ line), and days between last dose of the final chemotherapy regimen and death ( $\leq 79$ days) were independently and significantly associated with survival. Compared with patients who did not receive chemotherapy in the last 79 days of life, those who received chemotherapy in the last 79 days of life had a hazard ratio of 1.858 (95\% CI, 1.059-3.261; $\mathrm{P}=0.031$ ) for mortality. Patients who received $\leq 1$ chemotherapy regimen had a hazard ratio of 2.029 (95\% CI, 1.254-3.282; $\mathrm{P}=0.004$ ) for death as compared with patients who received $\geq 2$ chemotherapy regimens. For age ( $\leq 51$ years), the hazard ratio for death was 2.947 (95\% CI, 1.378-6.303; $\mathrm{P}=0.005)$ compared with patients aged $>51$ years.

Reasons for discontinuation of last-line chemotherapy. The reasons for discontinuation of last-line chemotherapy are presented in Table III. For patients who received chemotherapy in the last 79 days of life, the reason for discontinuation was a decrease in performance status in 51 cases; progressive disease in 6 cases; deterioration in disease condition in 4 cases; adverse events (appetite loss, nausea/vomiting or drug-induced pneumonia) in 4 cases; and death in 2 cases. For patients who did not receive chemotherapy in the last 79 days of life, the reason for discontinuation was a decrease in performance status in 9 cases, progressive disease in 8 cases, deterioration in disease condition in 3 cases, adverse events (drug-induced pneumonia and neuropathy) in 3 cases and patient wishes in 2 cases. There was a significant difference in the reasons for termination between the two groups $(\mathrm{P}=0.005)$. In addition, the median was 2 treatment lines (range, 1-5 lines) for both patients who received chemotherapy in the last 79 days of life (range, 1-5 lines) and patients who did not receive chemotherapy in the last 79 days of life (range, 1-4 lines; $\mathrm{P}=0.537$ ).

Cancer treatment received 79 days prior to final hospitalization. The treatment received by patients who were last hospitalized 79 days prior to mortality are presented in Table IV. A significantly higher number of patients who received chemotherapy in the last 79 days of life were hospitalized before death $(n=67)$ as compared with patients who did not receive chemotherapy in the last 79 days of life $(n=15 ; P<0.001)$. For patients who received chemotherapy in the last 79 days of life, the main reasons for the last hospitalization of life was appetite loss in 23 cases, fatigue in 15 cases, nausea/vomiting in 7 cases, dyspnea in 7 cases and pain in 6 cases. For patients who did not receive chemotherapy in the last 79 days of life, the main reasons for the last hospitalization of life was loss of appetite in 6 cases and pain in 4 cases. There was a significant difference in the reasons for the last hospitalization of life between the two groups $(\mathrm{P}<0.001)$.

\section{Discussion}

The purpose of the present study was to clarify the effect of the timing of treatment discontinuation on disease prognosis in patients receiving chemotherapy for advanced and recurrent gastric cancer. It was demonstrated that the following factors reduced the survival time in patients receiving chemotherapy 
Table I. Patient characteristics.

\section{Characteristic}

Datum

Patients, $\mathrm{n}$

Age, years, median (range)

Sex, male/female, $n$

Disease status, advanced/recurrent, $n$

Body surface area, $\mathrm{m}^{2}$, median (range)

$\mathrm{CrCl}, \mathrm{ml} / \mathrm{min}$, median (range)

Chemotherapy use

Regimens, $n$, median (range)

Proportion within 14 days of death, n (\%)

Proportion within 30 days of death, $\mathrm{n}(\%)$

Proportion within 60 days of death, $\mathrm{n}(\%)$

Proportion of oral drugs in last-line chemotherapy, n (\%)

Days between last dose of final chemotherapy

regimen and death, median (range)

Days between last dose of final chemotherapy

regimen and mortality, median (range)

Intravenous

Oral

Chemotherapy used, $n$

S-1 plus CDDP

S-1

SOX

S-1 plus DTX

PTX

PTX plus CDDP

PTX plus Ramucirumab

Ramucirumab

CPT-11

DTX

XELOX

XP

$\mathrm{XP}$ plus trastuzumab

Capecitabine

CDDP plus CPT-11

CDDP plus trastuzumab

$\mathrm{CrCl}$, creatinine clearance; CDDP, cisplatin; DTX, docetaxel; CPT-11, irinotecan; S-1, tegaful gimeracil oteracil potassium; SOX, S-1 plus Oxaliplatin; PTX, paclitaxel; XELOX, capecitabine plus oxaliplatin; XP, capecitabine plus CDDP; OS, overall survival.

for advanced and recurrent gastric cancer chemotherapy: Age $\leq 51$ years, receipt of $\leq 1$ line of chemotherapy, and receipt of chemotherapy in the last 79 days of life.

The development of anticancer drugs such as molecular target drugs has remarkably changed patient prognoses (1-13). Many studies have reported an association between continuation of cancer chemotherapy at the terminal stage and prognosis, and the timing of treatment discontinuation $(15,16,18-20)$. In the present study, the percentage of patients who received chemotherapy in the last 30 days of life (42\%) was higher than that previously reported (18-33\%) $(18,21-23)$. This is probably because treatment can be continued by advancing supportive therapy in many cases. However, aggressive chemotherapy at the terminal stage is more expensive and does not increase the survival time (18-20). The present study also revealed that receipt of chemotherapy in the last 79 days of life reduces the 
Table II. Multivariate analysis of prognostic factors associated with OS in patients with advanced and recurrent gastric receiving chemotherapy.

\begin{tabular}{|c|c|c|c|}
\hline Factor & Hazard ratio & $95 \% \mathrm{CI}$ & P-value \\
\hline \multicolumn{4}{|l|}{ Age, years } \\
\hline \multicolumn{4}{|l|}{$>51(\mathrm{n}=90)$} \\
\hline$\leq 51(\mathrm{n}=11)$ & 2.947 & $1.378-6.303$ & 0.005 \\
\hline \multicolumn{4}{|l|}{ Sex } \\
\hline \multicolumn{4}{|l|}{ Male $(n=69)$} \\
\hline Female $(n=32)$ & 0.713 & $0.423-1.200$ & 0.203 \\
\hline \multicolumn{4}{|l|}{ Disease status } \\
\hline \multicolumn{4}{|l|}{ Advanced $(\mathrm{n}=59)$} \\
\hline Recurrent $(n=42)$ & 1.843 & $0.244-13.942$ & 0.541 \\
\hline \multicolumn{4}{|l|}{ Metastatic sites, $\mathrm{n}$} \\
\hline \multicolumn{4}{|l|}{$>2(\mathrm{n}=9)$} \\
\hline$\leq 2(n=92)$ & 0.675 & $0.415-1.097$ & 0.675 \\
\hline \multicolumn{4}{|l|}{$\mathrm{BSA}, \mathrm{m}^{2}$} \\
\hline \multicolumn{4}{|l|}{$>1.56(\mathrm{n}=38)$} \\
\hline$\leq 1.56(\mathrm{n}=63)$ & 1.404 & $0.779-2.529$ & 0.258 \\
\hline \multicolumn{4}{|l|}{$\mathrm{CrCl}, \mathrm{ml} / \mathrm{min} / 1.73 \mathrm{~m}^{2}$} \\
\hline \multicolumn{4}{|l|}{$>66.1(\mathrm{n}=62)$} \\
\hline$\leq 66.1(\mathrm{n}=39)$ & 1.086 & $0.626-1.885$ & 0.768 \\
\hline \multicolumn{4}{|l|}{ Treatment lines, $\mathrm{n}$} \\
\hline \multicolumn{4}{|l|}{$>1(\mathrm{n}=70)$} \\
\hline$\leq 1(\mathrm{n}=31)$ & 2.029 & $1.254-3.282$ & 0.004 \\
\hline \multicolumn{4}{|c|}{$\begin{array}{l}\text { Days between last dose of final } \\
\text { chemotherapy regimen and death }\end{array}$} \\
\hline \multicolumn{4}{|l|}{$>79(\mathrm{n}=26)$} \\
\hline$\leq 79(\mathrm{n}=75)$ & 1.858 & $1.059-3.261$ & 0.031 \\
\hline \multicolumn{4}{|c|}{ Reasons for treatment discontinuation } \\
\hline \multicolumn{4}{|c|}{$\begin{array}{l}\text { Decrease in performance status and } \\
\text { deterioration of condition }(n=75)\end{array}$} \\
\hline $\begin{array}{l}\text { Progressive disease }(n=17) \\
\text { and patient wishes }\end{array}$ & 0.960 & $0.564-1.635$ & 0.879 \\
\hline
\end{tabular}

BSA, body surface area; $\mathrm{CrCl}$, creatinine clearance; $\mathrm{CI}$, confidence intervals; OS, overall survival.

OS. These findings suggest that continuation of chemotherapy until just before mortality does not prolong the survival time, even in patients with advanced and recurrent gastric cancer receiving chemotherapy.

Regarding the reasons for treatment discontinuation, a decrease in performance status was observed more frequently in patients who stopped chemotherapy in the last 79 days of life than in those who stopped chemotherapy prior to the last 79 days of life. It could not be clarified whether this decline was the result of disease progression or the final round of chemotherapy. However, a higher number of patients who received chemotherapy in the last 79 days of life were hospitalized prior to mortality than patients who stopped chemotherapy prior to the last 79 days of life. Keam et al (24) previously reported that patients who received chemotherapy in the last month of life had a shorter survival time and were hospitalized more frequently. Thus, chemotherapy may contribute to deterioration of the quality of life in patients who are approaching the end of their lives.

Previous studies have demonstrated that early intervention with palliative treatment improves the quality of life, including quality of terminal care, in patients with non-small cell lung cancer $(20,25)$. According to the abovementioned studies, there were no differences in the number of regimens of chemotherapy administered, between those who were provided early intervention with palliative treatment and those without early intervention with palliative treatment. However, the survival period from discontinuation of anticancer drug therapy to death was significantly prolonged by early intervention with palliative treatment, which improved accuracy in understanding patient prognoses and treatment goals. In addition, Greer et al (15) previously considered that such intervention reduced excessive chemotherapy at the terminal stages. In the present study, there was no significant difference in the number of chemotherapy 
Table III. Reasons for treatment discontinuation.

\begin{tabular}{|c|c|c|c|}
\hline Reason & $\begin{array}{l}\text { Patients who received } \\
\text { chemotherapy in the last } \\
79 \text { days of life, } n(n=75)\end{array}$ & $\begin{array}{l}\text { Patients who did not receive } \\
\text { chemotherapy in the last } \\
79 \text { days of life, } n(n=26)\end{array}$ & P-value \\
\hline Decrease in performance status & 51 & 9 & $0.005^{\mathrm{a}}$ \\
\hline Progressive disease & 6 & 8 & \\
\hline Deterioration in disease condition & 4 & 3 & \\
\hline Adverse events & 4 & 3 & \\
\hline Patient wishes & 0 & 2 & \\
\hline Other & 2 & 0 & \\
\hline
\end{tabular}

${ }^{a} \chi^{2}$ test of independence.

Table IV. The last hospitalization of life.

Patients who received chemotherapy in the last 79 days of life, $(n=75)$
Patients who did not receive chemotherapy in the last 79 days of life, $(n=26)$

Last hospitalization

$\begin{array}{lcc}\text { Yes } & 67 & 15 \\ \text { No } & 8 & 11 \\ \text { P-value } & <0.001^{\mathrm{a}} & <0.001^{\mathrm{a}}\end{array}$

${ }^{a} \chi^{2}$ test of independence.

regimens between patients who received chemotherapy in the last 79 days of life and those who did not. However, patients who discontinued treatment early exhibited a longer survival time. Nakano et al (25) reported that the rate of cancer progression and adverse events of chemotherapy are the major causes of differences in the period from discontinuation of chemotherapy to death; they also reported that it is possible to predict the disease progression to some extent during chemotherapy.

The American Society of Clinical Oncology has emphasized the need for realistic dialogue with patients (26). From the time of diagnosis, continued concrete discussion about the patient's condition is recommended, and specific discussion is recommended about the goal of chemotherapy, the effect and toxicity of chemotherapy, change to other treatments and lifespan. Furthermore, absence of dialogue in the presence or absence of a medical condition and palliative care (hospice) with the doctor was reported as a factor leading to administration of chemotherapy until just prior to mortality (27). Early prognosis of oncoming mortality may result in better quality of care and use of resources $(22,28-30)$. Therefore, it is important to discuss the optimal timing for discontinuation of chemotherapy with patients from the beginning of treatment.

Age and number of treatment lines were also factors that influenced the survival period; these are characteristic of gastric cancer. In gastric cancer, the polymer type of cancer is more common in men, and its incidence increases with age. In contrast, the low-molecular type tends to be more prevalent in women and young people (20-39 years) (31), this type of gastric cancer is difficult to detect and progresses rapidly. This suggests that young people with this type of cancer have a short survival time and could not continue treatment.

However, it must be taken into consideration that in the results of the present investigation, patient disease stage and various chemotherapy regimens may have affected patient prognosis. As such, careful decisions on continuation or discontinuation of treatment may have to be made by predicting disease state even in cases in which the patient undergoes more intensive chemotherapy.

In conclusion, due to the development of chemotherapy for advanced and recurrent gastric cancer, many drugs are used for treatment of patients, which greatly improves the disease prognosis. However, to obtain a better prognosis, it is important to discuss the timing of discontinuation of chemotherapy by predicting the disease state rather than continuing chemotherapy until just prior to mortality. For pharmacists, this finding can serve as an indicator for continuing cancer chemotherapy or palliative care.

\section{Acknowledgements}

Not applicable.

\section{Funding}

No funding was received.

\section{Availability of data and materials}

The datasets used and/or analyzed during the current study are available from the corresponding author on reasonable request. 


\section{Authors' contributions}

MK, SK, MG, MI, EU, HT and TY conceived and designed the present study. MK and TY acquired the data. MK, SK, MG, MI, EU, HT and TY drafted the manuscript. All authors read and approved the final manuscript.

\section{Ethics approval and consent to participate}

The present study was approved by the Institutional Review Board of Ogaki Municipal Hospital (Ogaki, Japan). The requirement of informed consent was waived by the Institutional Review Board.

\section{Patient consent for publication}

Not applicable.

\section{Competing interests}

The authors declare that they have no competing interests.

\section{References}

1. Boku N, Yamamoto S, Fukuda H, Shirao K, Doi T, Sawaki A, Koizumi W, Saito H, Yamaguchi K, Takiuchi $\mathrm{H}$, et al; Gastrointestinal Oncology Study Group of the Japan Clinical Oncology Group: Fluorouracil versus combination of irinotecan plus cisplatin versus S-1 in metastatic gastric cancer: A randomised phase 3 study. Lancet Oncol 10: 1063-1069, 2009.

2. Koizumi W, Narahara H, Hara T, Takagane A, Akiya T, Takagi M, Miyashita K, Nishizaki T, Kobayashi O, Takiyama W, et al: S-1 plus cisplatin versus S-1 alone for first-line treatment of advanced gastric cancer (SPIRITS trial): A phase III trial. Lancet Oncol 9: 215-221, 2008.

3. Bang YJ, Van Cutsem E, Feyereislova A, Chung HC, Shen L, Sawaki A, Lordick F, Ohtsu A, Omuro Y, Satoh T, et al ToGA Trial Investigators: Trastuzumab in combination with chemotherapy versus chemotherapy alone for treatment of HER2-positive advanced gastric or gastro-oesophageal junction cancer (ToGA): A phase 3, open-label, randomised controlled trial. Lancet 376: 687-697, 2010.

4. Ohtsu A, Shah MA, Van Cutsem E, Rha SY, Sawaki A, Park SR, Lim HY, Yamada Y, Wu J, Langer B, et al: Bevacizumab in combination with chemotherapy as first-line therapy in advanced gastric cancer: A randomized, double-blind, placebo-controlled phase III study. J Clin Oncol 29: 3968-3976, 2011.

5. Cunningham D, Starling N, Rao S, Iveson T, Nicolson M, Coxon F, Middleton G, Daniel F, Oates J and Norman AR; Upper Gastrointestinal Clinical Studies Group of the National Cancer Research Institute of the United Kingdom: Capecitabine and oxaliplatin for advanced esophagogastric cancer. N Engl J Med 358: 36-46, 2008.

6. Yamada Y, Higuchi K, Nishikawa K, Gotoh M, Fuse N, Sugimoto N, Nishina T, Amagai K, Chin K, Niwa Y, et al: Phase III study comparing oxaliplatin plus S-1 with cisplatin plus S-1 in chemotherapy-naïve patients with advanced gastric cancer. Ann Oncol 26: 141-148, 2015.

7. Shah MA, Bang YJ, Lordick F, Alsina M, Chen M, Hack SP, Bruey JM, Smith D, McCaffery I, Shames DS, et al: Effect of fluorouracil, leucovorin, and oxaliplatin with or without onartuzumab in HER2-negative, MET-positive gastroesophageal adenocarcinoma: The METGastric randomized clinical trial. JAMA Oncol 3: 620-627, 2017.

8. Yoon HH, Bendell JC, Braiteh FS, Firdaus I, Philip PA, Cohn AL, Lewis N, Anderson DM, Arrowsmith E, Schwartz JD, et al: Ramucirumab combined with FOLFOX as front-line therapy for advanced esophageal, gastroesophageal junction, or gastric adenocarcinoma: A randomized, double-blind, multicenter Phase II trial. Ann Oncol 27: 2196-2203, 2016.
9. Kurokawa Y, Sugimoto N, Miwa H, Tsuda M, Nishina S, Okuda H, Imamura H, Gamoh M, Sakai D, Shimokawa T, et al: Phase II study of trastuzumab in combination with S-1 plus cisplatin in HER2-positive gastric cancer (HERBIS-1). Br J Cancer 110: 1163-1168, 2014.

10. Miura Y, Sukawa Y, Hironaka S, Mori M, Nishikawa K, Tokunaga S, Okuda H, Sakamoto T, Taku K, Nishikawa K, et al: Five-weekly S-1 plus cisplatin therapy combined with trastuzumab therapy in HER2-positive gastric cancer: A phase II trial and biomarker study (WJOG7212G). Gastric Cancer 21: 84-95, 2018.

11. Wilke H, Muro K, Van Cutsem E, Oh SC, Bodoky G, Shimada Y, Hironaka S, Sugimoto N, Lipatov O, Kim TY, et al; RAINBOW Study Group: Ramucirumab plus paclitaxel versus placebo plus paclitaxel in patients with previously treated advanced gastric or gastro-oesophageal junction adenocarcinoma (RAINBOW): A double-blind, randomised phase 3 trial. Lancet Oncol 15: 1224-1235, 2014 .

12. Hironaka S, Ueda S, Yasui H, Nishina T, Tsuda M, Tsumura T, Sugimoto N, Shimodaira H, Tokunaga S, Moriwaki T, et al: Randomized, open-label, phase III study comparing irinotecan with paclitaxel in patients with advanced gastric cancer without severe peritoneal metastasis after failure of prior combination chemotherapy using fluoropyrimidine plus platinum: WJOG 4007 trial. J Clin Oncol 31: 4438-4444, 2013.

13. Kang YK, Boku N, Satoh T, Ryu MH, Chao Y, Kato K, Chung HC, Chen JS, Muro K, Kang WK, et al: Nivolumab in patients with advanced gastric or gastro-oesophageal junction cancer refractory to, or intolerant of, at least two previous chemotherapy regimens (ONO-4538-12, ATTRACTION-2): A randomised, double-blind, placebo-controlled, phase 3 trial. Lancet 390: 2461-2471, 2017.

14. American Society of Clinical Oncology: Outcomes of cancer treatment for technology assessment and cancer treatment guidelines. J Clin Oncol 14: 671-679, 1996.

15. Greer JA, Pirl WF, Jackson VA, Muzikansky A, Lennes IT, Heist RS, Gallagher ER and Temel JS: Effect of early palliative care on chemotherapy use and end-of-life care in patients with metastatic non-small-cell lung cancer. J Clin Oncol 30: 394-400, 2012.

16. Saito AM, Landrum MB, Neville BA, Ayanian JZ and Earle CC: The effect on survival of continuing chemotherapy to near death. BMC Palliat Care 10: 14, 2011.

17. Kanda Y: Investigation of the freely available easy-to-use software 'EZR' for medical statistics. Bone Marrow Transplant 48: 452-458, 2013.

18. Näppä U, Lindqvist O, Rasmussen BH and Axelsson B: Palliative chemotherapy during the last month of life. Ann Oncol 22: 2375-2380, 2011

19. Lewin SN, Buttin BM, Powell MA, Gibb RK, Rader JS, Mutch DG and Herzog TJ: Resource utilization for ovarian cancer patients at the end of life: How much is too much? Gynecol Oncol 99: 261-266, 2005

20. Temel JS, Greer JA, Muzikansky A, Gallagher ER, Admane S, Jackson VA, Dahlin CM, Blinderman CD, Jacobsen J, Pirl WF, et al: Early palliative care for patients with metastatic non-small-cell lung cancer. N Engl J Med 363: 733-742, 2010.

21. Bjordal K and Aass N: Palliative cytostatic treatment. Tidsskr Nor Laegeforen 124: 3206-3207, 2004 (In Norwegian).

22. Hemminki K and Chen B: Familial risk for colorectal cancers are mainly due to heritable causes. Cancer Epidemiol Biomarkers Prev 13: 1253-1256, 2004.

23. Kim A, Fall P and Wang D: Palliative care: Optimizing quality of life. J Am Osteopath Assoc 105 (Suppl 5): S9-S14, 2005.

24. Keam B, Oh DY, Lee SH, Kim DW, Kim MR, Im SA, Kim TY, Bang YJ and Heo DS: Aggressiveness of cancer-care near the end-of-life in Korea. Jpn J Clin Oncol 38: 381-386, 2008.

25. Nakano K, Yoshida T, Furutama J and Sunada S: Quality of end-of-life care for patients with metastatic non-small-cell lung cancer in general wards and palliative care units in Japan. Support Care Cancer 20: 883-888, 2012.

26. Peppercorn JM, Smith TJ, Helft PR, Debono DJ, Berry SR, Wollins DS, Hayes DM, Von Roenn JH and Schnipper LE; American Society of Clinical Oncology: American society of clinical oncology statement: Toward individualized care for patients with advanced cancer. J Clin Oncol 29: 755-760, 2011.

27. Ahsan H, Neugut AI, Garbowski GC, Jacobson JS, Forde KA, Treat MR and Waye JD: Family history of colorectal adenomatous polyps and increased risk for colorectal cancer. Ann Intern Med 128: 900-905, 1998. 
28. Hashimoto K, Yonemori K, Katsumata N, Hotchi M, Kouno T, Shimizu C, Tamura K, Ando M, Takeuchi M and Fujiwara Y: Factors that affect the duration of the interval between the completion of palliative chemotherapy and death. Oncologist 14: 752-759, 2009.

29. Asola R, Huhtala H and Holli K: Intensity of diagnostic and treatment activities during the end of life of patients with advanced breast cancer. Breast Cancer Res Treat 100: 77-82, 2006.

30. Thorne SE, Bultz BD and Baile WF; SCRN Communication Team: Is there a cost to poor communication in cancer care? A critical review of the literature. Psychooncology 14: 875-884, discussion 885-886, 2005.
31. Miyamoto T, Ogawa M, Okagawa K, Ogawa Y, Fujimoto J, Kawasaki K, Mizunoya S, Fujiyama T, Kido Y, Shiozaki H, et al: The histological types of eary and simulating advanced gastric cancer, and their clinicopathological character -with special refemence to lymphnode metastasis and lymphatic invasion. Nihon Shokaki Geka Gakkai Zasshi 16: 1772-1777, 1983 (In Japanese). 